Cadernos de Semiótica Aplicada

Vol. 4.n.2, dezembro de 2006

\title{
DE PEIRCE A CHARAUDEAU: As qualidades do poético ilustradas por Ziraldo
}

\author{
FROM PEIRCE TO CHARAUDEAU \\ The poetic qualities illustrated by Ziraldo
}

\author{
Beatriz dos Santos Feres \\ UFF - Universidade Federal Fluminense e \\ UNIPLI - Centro Universitário Plínio Leite
}

\begin{abstract}
Resumo: Este trabalho, privilegiando a emergência do sentido poético, pretende analisar aspectos do processo semiótico. Nessa análise, a semiose é explicada não só pelos diferentes modos de significação - icônico, indicial e simbólico (PEIRCE, 2003) —, mas também pela confluência de elementos oriundos da superfície textual, do discurso e da situação comunicativa (CHARAUDEAU, 2001). A reflexão será ilustrada por textos sincréticos de literatura infantil representados por obras de Ziraldo Alves Pinto: $O$ menino quadradinho (1989), O menino mais bonito do mundo (1994a), Uma historinha sem (1) sentido (1994b) e Flicts (1999).
\end{abstract}

Palavras-chave: semiose; sincretismo; literatura infantil; Ziraldo; poético.

\begin{abstract}
This paper, which main purpose is the emergence of the poetic sense, intends to analyze some aspects of semiotic process. In this analysis, the semiotic process is explained not only by the iconic, indicial and symbolic ways of signification (Peirce, 2003), but also by the confluence of elements from the textual surface, the discursive universe and the communicative situation (Charaudeau, 2001). The reflection will be illustrated by the children's literature syncret texts represented by Ziraldo Alves Pinto books: $O$ menino quadradinho (1989), O menino mais bonito do mundo (1994a), Uma historinha sem (1) sentido (1994b) and Flicts (1999).
\end{abstract}

Keywords: semiose; syncretism; children's literature; Ziraldo; poetic. 
CASA, Vol.4, n.2, dezembro de 2006

\section{Considerações para "escrever com mão alheia"}

Affonso Romano de Sant'Anna (s/d) defende a idéia de que "ler é uma forma de escrever com mão alheia". Se observado o percurso dos estudos da linguagem e, mais especificamente, da investigação sobre o ato de ler nas últimas décadas, a expressão "escrever com mão alheia" (legando ao leitor a autoria do sentido que constrói), assume uma roupagem estampada de sujeitos, interação, discursividade, aspectos situacionais e sincretismo sígnico que substitui a passividade do leitor, ou a total permissividade de outras eras, pelo papel de sujeito interagente, re-conhecedor, no escrito/inscrito a ele oferecido por uma mão alheia, o sentido possível, marcado textualmente, mas só revelado através de sua atuação sobre o mundo semiotizado.

Neste estudo, a construção de sentido em textos sincréticos do gênero literatura infantil, aqui representada pelos livros de Ziraldo $O$ menino quadradinho (1989), O menino mais bonito do mundo (1994a), Uma historinha sem (1) sentido (1994b) e Flicts (1999), do qual participam complementarmente o verbal e o visual, pressupõe a identificação dos diferentes signos conformadores (ou co-formadores) de sua superfície textual. Com o objetivo de analisar a semiose ocorrida nesse tipo de texto, assim como a emergência do poético a partir das qualidades suscitadas pela superfície textual, serão utilizadas noções extraídas da Semiótica (PEIRCE, 2003; SANTAELLA, 2000) e da Teoria Semiolingüística de Análise do Discurso (CHARAUDEAU, 2001).

\section{De Peirce a Charaudeau}

“A linguagem não está em nós. Somos nós que estamos na linguagem” (Peirce, Apud SANTAELLA, 2000, p. 63). A afirmação do semioticista nos revela o poder da linguagem: precedendo-nos e sendo, da mesma forma, posterior à nossa existência, consegue fazer com que utilizemos seus signos para dar sentido ao mundo, às nossas experiências, seja percebendo a realidade, seja expressando nossa visão única sobre a vida. Como seres sociais, localizamo-nos no interior da linguagem com o intuito de usufruir daquilo que é comum ao outro, caso contrário, não seria possível a comunicação, a interação, a troca. Os signos significam com o apoio daquilo que fora experienciado anteriormente, num re-conhecimento das relações inter e intrasignificativas que os constituem como tal. Da mesma forma, só se criam signos novos a partir da infinitude das cadeias sígnicas, sempre determinantes de novas significações.

Ao postular uma teoria geral dos signos, Peirce pretendia compreender como as diversas linguagens conseguem significar e, para isso, estudou a relação triádica entre signo (veículo que comunica à mente algo do exterior), objeto (aquilo em cujo lugar o signo está) e interpretante (a idéia que o signo provoca), que corresponde, na concepção do estudioso, à noção de semiose, e, criou, para tal, categorias de signos, os ícones, os índices e os símbolos - entre outras importantes contribuições.

Grosso modo, são considerados icônicos os signos que representam seus objetos "principalmente através de sua similaridade, não importa qual seja seu modo de ser" (PEIRCE, 2003, p. 64); são indiciais os signos que assinalam a junção entre duas porções de experiência (op.cit., p. 67), ou seja, dependem da contigüidade com o objeto que representam; já os símbolos são signos "cujo caráter representativo consiste exatamente em ser uma regra que determina seu Interpretante" (op.cit., p. 71), ou, em outras palavras, símbolos são signos convencionais, que atuam sob regras socialmente impostas. Embora não se encontre um tipo 
de signo "em estado puro", ou sem a impregnância do(s) outro(s) tipo(s), há sempre um caráter que se sobrepõe aos outros, de acordo com a forma como é determinado seu Interpretante, ou seu significado, que, por conta disso, o nomeia.

[...] quando se trata de um signo atual, concretamente manifesto, este vem sempre com misturas de caracteres icônicos, indiciais e simbólicos. Nenhum signo atual aparece em estado puro. Sem se fazer acompanhar por índices, por exemplo, o símbolo estaria destituído de poder de referencialização e, sem o ícone, despido de qualquer poder de imaginação. [...] As linguagens mais perfeitas são aquelas que mantêm os três níveis sígnicos em estado de equilíbrio e complementaridade. (SANTAELLA, 2000, p. 27)

A Semiótica peirceana privilegia o estudo da autogeração sígnica e suas relações constitutivas; não trata especificamente da subjetividade própria do processo comunicativo/interativo, alvo de nosso interesse. Apesar disso, não exclui das análises que engendra a presença do sujeito da linguagem, pelo menos, como posição no mundo, social, ocupada pelo intérprete - principalmente quando é explanado o que é índice, na relação "direta" que mantém com a coisa significada, ou seja, o significado do índice pertence, essencialmente, à situação a que se refere.

[...] Suponhamos que dois homens se encontrem numa estrada e que um deles diga ao outro: "A chaminé daquela casa está acesa". O outro olha à sua volta e vê uma casa com cortinas verdes e varanda e com uma chaminé da qual sai fumaça. Anda algumas milhas e encontra um segundo viajante. Com simplicidade, diz: "A chaminé daquela casa está acesa"."Que casa?", pergunta o outro. "Oh, uma casa com cortinas verdes e uma varanda", responde o simplório. "Onde está a casa?" pergunta o forasteiro. Ele deseja um índice que ligue a informação que lhe dão com a casa pretendida. Palavras apenas não podem fazê-lo. Os pronomes demonstrativos "este" e "aquele" são índices. Pois levam o ouvinte a usar seus poderes de observação, estabelecendo dessa maneira uma conexão real entre sua mente e o objeto. (PEIRCE, 2003, p. 68)

Como se vê no exemplo proposto pelo próprio estudioso, a relação indicial (que também poderia ser denominada dêitica) pressupõe um vínculo com a situação enunciativa, com os sujeitos que a vivenciam, a fim de estabelecer significados. É verdade, porém, que a simples referência à situação que atualiza os signos não pode tão-somente fazer saber todo o significado pretendido. Observem-se outros exemplos oferecidos por Peirce (2003, p. 67).

Um barômetro a marcar pressão baixa e ar úmido é índice de chuva; isto é, supomos que as forças da natureza estabelecem uma conexão provável entre o barômetro que marca pressão baixa com o ar úmido e a chuva iminente. Um cata-vento é um índice da direção do vento dado que, em primeiro lugar, ele realmente assume a mesma direção do vento, de modo tal que há uma conexão real entre ambos, e, em segundo lugar, somos constituídos de tal forma que, quando vemos um cata-vento apontando numa certa direção, nossa atenção é atraída para essa direção e, quando vemos o cata-vento girando com o vento, somos forçados, por uma lei do espírito, a pensar que essa direção tem uma relação com o vento. A estrela polar é um índice, ou um dedo indicador, que nos mostra onde fica o Norte. Um nível de bolha, ou um fio de prumo, é um índice da direção vertical. [...]

Nos casos mencionados, o poder sígnico dos elementos está ligado, em princípio, a uma conexão física entre objeto e interpretante, isto é, indicialmente, mas também conta com um aspecto simbólico, já que os significados trazidos à tona dependem também de uma 
aprendizagem, de uma intervenção cognitiva, mediada pelo social, exigente de um conhecimento prévio: a estrela polar só indicará o Norte para o intérprete conhecedor desse vínculo, e do que significa "Norte", noção que extrapola o momento/espaço enunciativo; o barômetro precisa, antes de indicar chuva, ser reconhecido, ele mesmo, como objeto significante, e esse fato depende de uma experiência anterior mais ou menos mediada pelo social, ou seja, simbólica. Além disso, o aspecto icônico não pode ser menosprezado: a correspondência entre, de um lado, o ponteiro do barômetro e, de outro, a pressão atmosférica e o ar úmido, contém, em si mesma, uma relação de similaridade, de espelhamento, própria do icônico. A percepção da marca estabelecida pelo ponteiro faz com que apareça o significado "chuva iminente", mas numa relação concomitantemente icônica, indicial e simbólica.

Já para a Semiolingüística, o processo de semiotização do mundo enfatiza a inclusão dos sujeitos da linguagem (sendo conhecida, por isso mesmo, a Teoria dos Sujeitos da Linguagem), distribuídos de acordo com o papel que desempenham no processo de construção do sentido: o sujeito-comunicante e o sujeito-interpretante, pertencentes ao mundo "real", externo ao texto, desdobram-se em, respectivamente, sujeito-enunciador e sujeitodestinatário, vinculados ao mundo da palavra, numa projeção que o sujeito-comunicante faz de si mesmo e do outro a quem se refere num contrato comunicativo determinado pela posição de cada um desses sujeitos, inseridos num tempo/espaço específico, de acordo com o papel social que exercem.

A semiotização ocorre em dois planos: o superficial, aparente, concreto, e o discursivo, implícito, inferível. De acordo com Charaudeau (1983), o primeiro plano é percebido num esforço de compreensão textual e o segundo é apreendido num movimento trans-textual, que ultrapassa o limite do concreto, do aparente; é o plano da interpretação. Para se fazer compreender, ou para compreender o outro, é necessário saber selecionar e combinar os signos, de maneira a construir uma trama sígnica aparente, que representa o mundo (ou um mundo). Essa trama, ou texto, no entanto, mostra-se repleta de marcas, indícios de uma orientação externa a ela, do nível da interpretação, que a conforma: são as orientações vindas do que é discursivo, apoiado no social, no imaginário e no ideológico; ou oriundas do que é situacional, referente aos papéis desempenhados pelos sujeitos, à sua simetria (ou assimetria) na interação, ao momento/espaço da enunciação.

Charaudeau (2001) postula a noção de competência de linguagem, referente à capacidade que o sujeito (comunicante ou interpretante) deve dominar para construir o sentido textual: "Para que haya sentido, es preciso que lo dicho esté vinculado con lo conjunto de las condiciones dentro de las cuales lo dicho esté dicho" (p. 13). É uma competência subdividida em três tipos intensamente relacionados - situacional, discursivo e semiolingüístico - de acordo com os três níveis a que pertencem os recursos de linguagem usados para a construção do sentido.

Que se diga que se trata de tres competencias o de una sola compuesta por tres aptitudes del hacer, lo que importa es que se aborde dicha competencia (por mi parte, tiendo a hablar de "una triple competencia de lenguaje") como el resultado de un movimiento de ida y vuelta permanente entre la aptitud para reconocer las condiciones sociales de comunicación, la aptitud para conocer-manejar las estrategias del discurso y la aptitud para reconocer-manejar los sistemas semiolingüísticos, las cuales se hallan mutuamente insertadas. Esta competencia si bien no puede ser un juicio, tal como en el uso cotidiano, es, en cambio, el resultado de un andamiaje del cual se articulan saber-hacer y conocimientos. (CHARAUDEAU, 2001, p. 178) 
Remetendo-se à metáfora do iceberg, a pequena porcentagem visível "acima do nível do mar", aquilo que está "na superfície", corresponderia ao nível semiolingüístico. O nãodito, as informações pressupostas, as ironias, a pluralidade de sentidos do texto literário, enfim, tudo o que está além do texto, além do que é concretamente percebido, estaria "abaixo do nível do mar"; pertenceria, então, aos níveis discursivo e situacional — ou estaria simplesmente na relação abstrata entre os três níveis.

Muitas vezes a separação desses níveis é tênue, ou quase impossível, visto que a identificação dos recursos de linguagem utilizados na construção do sentido parte de algum elemento formal (nível semiolingüístico), liga-se a um pressuposto discursivo (nível discursivo) e está seriamente comprometido com a situação que preside o contrato comunicativo (nível situacional), em virtude da imersão enunciativa que sofre. Ainda que o nível discursivo abarque uma quantidade infinita de recursos, é o nível situacional que determina o acionamento, ou o reconhecimento de cada um deles pelos sujeitos envolvidos no contrato comunicativo, a partir dos elementos (percebidos como marcas, ou como "pistas") oferecidos pela superfície textual.

\section{Entre a palavra e a imagem}

Na leitura, a competência semiolingüística (relativa a esse nível de construção textual) abarca, a princípio, a capacidade de reconhecer os signos; depois, é preciso saber relacionálos não só entre si, mas também ao contexto - sempre levando em consideração os elementos trazidos pela situação comunicativa. No caso do texto sincrético, ou misto, de literatura infantil, o nível semiolingüístico opera com signos icônicos, além de se valer da palavra. Esses dois tipos sígnicos obedecem a certas estratégias de leitura, ora de mesma natureza, ora de natureza diversa.

A diferença básica entre o signo verbal e o não-verbal, pertinente ao ato de leitura, diz respeito à sua maneira de significar. O signo não-verbal, sobretudo o figurativo, primeiramente exige do leitor a percepção, o re-conhecimento, através dele, dos seres do mundo iconicamente (em outras palavras, através da semelhança que esses signos estabelecem, eles próprios, com aquilo a que se referem).

Logo a seguir, na relação entre esse signo e os demais que constituem o texto, assim como entre ele e a situação comunicativa, o sujeito-interpretante "des-cobre" seu "sentido segundo", aquele que contribui para a construção do macro-sentido textual. Já com as palavras, esse processo é mais lento por causa de seu duplo processamento: inicia-se com a compreensão do simbólico (palavras); passa-se à identificação de sua "transparência" (iconicidade), ou de sua "opacidade" (movimento indicial ou novamente simbólico) e, finalmente, obtém-se a interpretação do sentido.

Além disso, as imagens trazem, aparentemente, um caráter universal, visto que o homem as produz desde a pré-história até nossos dias - e a similaridade entre esses elementos e a realidade que representam induz a esse engano. Isso dá a impressão de que a leitura desses elementos é "natural", ou "automática"; contudo, segundo Joly (1996, p. 99) "a interpretação das formas, assim como a das ferramentas plásticas, é essencialmente antropológica e cultural".

Por essas características, o signo icônico atrai o leitor pela aparente "facilidade" de leitura, mas está, o tempo todo, exigindo uma outra leitura, mais profunda, sempre ativadora do plano discursivo/situacional, para permitir sua interpretação. São ícones incessantemente 
CASA, Vol.4, n.2, dezembro de 2006

transformados em índices e símbolos, que precisam ser, além de reconhecidos/compreendidos, interpretados.

A confusão é freqüentemente feita entre percepção e interpretação. De fato, reconhecer este ou aquele motivo nem por isso significa que se esteja compreendendo a mensagem da imagem na qual o motivo pode ter uma significação bem particular, vinculada tanto a seu contexto interno quanto ao de seu surgimento, às expectativas e conhecimentos do receptor. [...] Portanto, ainda hoje, reconhecer motivos nas mensagens visuais e interpretá-los são duas operações mentais complementares, mesmo que tenhamos a impressão de que são simultâneas.

Por outro lado, o próprio reconhecimento do motivo exige um aprendizado. [...] É esse aprendizado, e não a leitura da imagem, que é feito de maneira "natural" na nossa cultura, na qual a representação pela imagem figurativa tem tanta importância. (JOLY, 1996, p. 42-3)

Percebe-se, pois, que a referência quase imediata ao mundo propiciada pelo signo icônico - sobretudo o figurativo - não pressupõe uma interpretação automática: é necessário recorrer à "significação segunda", à conotação imagística. Conforme Barthes (Apud JOLY, 1996, p. 83), a imagem figurativa constitui um signo pleno (um significante ligado a um significado), que se torna significante de um significado segundo, perfazendo um circuito de significação. Joly (op.cit., p. 83) explica:

Foi assim que Barthes conceitualizou e formalizou a leitura "simbólica" de imagem e, mais particularmente, da imagem publicitária. Para ele, esse processo de conotação é constitutivo de qualquer imagem, mesmo das mais "neutralizantes", como a fotografia, por exemplo, pois não existe imagem "adâmica". Que o motor dessa leitura segunda, ou interpretação, seja a ideologia, para uma sociedade e história determinadas, em nada invalida o fato de que, para Barthes, uma imagem pretende dizer algo diferente do que representa no primeiro grau, isto é, no nível da denotação.

Essa leitura segunda ou interpretação de que trata Joly ao se referir a Barthes, liga-se ao plano discursivo da linguagem, que leva em consideração aspectos outros que se localizam além da superfície textual, visível, primeiramente reconhecida. Esse duplo processo é explorado pelos lingüistas, em relação ao signo verbal, para se referir ao sentido discursivo, dependente do cálculo interpretativo.

Afirmando que o plano do sentido é duplamente semiótico, Coseriu (1980) revela a dupla função do significado lingüístico (no plano da língua), que, além de fazer uma referência ao mundo, permite que esse conteúdo veiculado pelo signo sirva de "significante" para um outro significado, específico à enunciação a que se incorpora, agora denominado sentido. Charaudeau, evidenciando o tipo de relações necessárias para a obtenção desse sentido, chama-o discursivo. O que Barthes postula a respeito da imagem figurativa, portanto, abarca, na verdade, a constituição de todo e qualquer signo, já que todo processo de significação que se origina no texto pressupõe a relação de cada elemento sígnico com o sistema ao qual pertence e com os fatores externos que regem a textualidade.

A competência semiolingüística, portanto, exige do sujeito-interpretante, em primeiro lugar, uma capacidade de reconhecimento dos signos que compõem a superfície textual e, em segundo, uma habilidade para relacionar essa evidência aos fatores "invisíveis", tanto do nível discursivo quanto situacional, que serão, eles próprios, as marcas textuais dos conteúdos implícitos e das referências à situação comunicativa. 
De acordo com Joly (1996), a análise dos diversos elementos (verbais ou não-verbais) que constituem o texto pode ser feita pela oposição e pela segmentação — ainda que, para a autora, o estudo da linguagem verbal seja mais simples, por causa de sua descontinuidade que favorece o isolamento das unidades discretas que a formam. A linguagem visual apresenta maior dificuldade devido à continuidade de seus elementos, que podem ser interpretados, sobretudo, pelo que não são, através de associações mentais que permitem, por permutação, a distinção de elementos "relativamente autônomos".

Ainda quanto à diferença entre a análise do signo verbal e do não-verbal, Almeida (1999, p. 26) diz:

A “imagem" acústica do signo lingüístico é definida com precisão, pois ele se articula a partir de um número reduzido de unidades mínimas dotadas de características distintivas.

A linguagem icônica, por sua vez, flexibiliza a articulação do signo visual. O significante não é identificado a uma estrutura formal rígida, composta por unidades mínimas isoláveis. As próprias características "articulatórias" mais evidentes dos significantes visuais (comprimento, espessura, nitidez, contraste, cor etc.) não são objeto de um consenso como os fonemas. Não se estabelece, a partir delas, um jogo de oposições binárias ou radicais (espesso $x$ não espesso; comprido $x$ não comprido); não oscilam entre o $\operatorname{sim}$ e o não. Ao contrário, deslocam-se do mais para o menos e vice-versa. Não são, portanto, traços distintivos.

Cada tipo de signo, portanto, guarda sua característica e se articula com outros signos de forma diferenciada, mas, na convergência de suas atuações para finalizar o sentido textual, privilegia-se o que significam em função do todo, um pouco em detrimento de como significam, acima de tudo porque a linguagem visual estará sempre "mais sujeita às variações idioletais do que a verbal, embora conserve seu caráter social, convencional, sem o qual não seria uma linguagem, nem haveria comunicação" (ALMEIDA, 1999, p. 27). Na junção dessas diversas linguagens, pode nascer, na opacidade do texto, o que há de original, desautomatizado, plurissignificativo, poético e lúdico.

\section{A originalidade do texto poético}

Para Peirce, o signo estético apresenta-se contraditoriamente, pois atribui uma "afinidade intelectual", consciente, representativa da "totalidade do Sentimento" experimentada na fruição estética. Em outras palavras, é um signo que se pretende sensação, sentimento; é um símbolo (convenção) que se pretende ícone (qualidade). Por isso, pode-se afirmar a singularidade desse signo, que exige do leitor não só a exacerbação de uma competência da linguagem, mas de uma outra, da sensibilidade: uma competência fruitiva.

Assim sendo, um texto poético, densamente marcado por mecanismos de sensibilização (tanto sensorial quanto emotiva), abriga um conjunto de recursos que emergem do processo de semiotização através dos níveis semiolingüístico, discursivo e situacional às vezes privilegiando elementos de um único nível, mas quase sempre se valendo de relações equilibradas entre os três. São recursos que buscam a surpresa, a originalidade, o impacto, a

ruptura, com o propósito de provocar uma resposta sensível, emocional, anterior mesmo (no sentido de mais imediata) à apreensão do sentido-interpretado e, conseqüentemente, suscitar o gosto, a fruição.

A "dimensão maior" do texto poético é fluida, percebida (sentida) ora mais, ora menos em função do investimento "sensível" do leitor em relação ao texto, ou do "afetamento" sofrido por ele internamente durante o ato de ler. Dessa forma, "sentir-se tocado pelo texto", 
como defende Zumthor (2000), é expressão quase literal; significa deixar-se invadir pelas sensações/sentimentos, que emanam do "laço pessoal" estabelecido entre leitor e texto. É esse sentimento de reconhecer-se tocado, atingido, transformado que constitui a dimensão poética. É a latente dimensão do fruir, viabilizada pelo texto poético, que fornece ao leitor elementos para despertar o sentimento (aqui entendido como processo de sentir) e, assim, faz-se convite (irrecusável); por isso "frouxo" em termos de objetividade, por isso mais "aberto" quanto à interpretação, por isso necessariamente "original".

Originalidade é a característica primordial do texto poético. Para entender seu papel no universo da poesia, é preciso retornar à idéia peirceana da primeiridade e analisar as diferentes maneiras de o texto ser poético e, conseqüentemente, ou concomitantemente, ser um texto de fruição.

Para Peirce, a originalidade é uma característica que "designa o ser tal como ele é, em nível primário" (ARAÚJO, 2004, p. 47), sem nem mesmo ter significado, ou melhor, sem nem mesmo ter sido significado, sem ter sido veiculado por um signo. É ser o que é, antes de se ter a consciência de que algo é (a consciência já corresponderia a uma secundidade). A originalidade é própria da Qualidade, da sensação pura, ainda não respondida por uma tentativa de significação. Ser original é guardar a possibilidade de ser a origem de uma sensação (reação reconhecida na secundidade) que pode vir a ser significada (na terceiridade, por um símbolo). A originalidade, portanto, implica uma "primeiridade", que é a simples existência das coisas:

(Primeiridade) são as coisas fora de qualquer suporte ou de relação referencial, tais como: espirrar nesse momento, ter nascido no século passado na Terra e não em Marte, o ruído das teclas do computador. No nível da primeiridade, tem-se a novidade, vida, liberdade, tudo o que pode ser, os fenômenos simples e livres, completos em si. Já em outro nível, o futuro se apresenta nas formas mentais, intenções e expectativas. (ARAÚJO, 2004, p. 47)

O texto do dia-a-dia, de compreensão automática, torna-se transparente, apenas meio de comunicação; na condição de símbolo, de convenção, funciona como lei, por isso não causa estranheza, pois o que interessa é seu conteúdo e não sua forma. Precisa ser discreto, quase imperceptível, "desimportante" para informar melhor, mais claramente. Não interessa como ele é, mas o que diz. Sua função está além dele, está em apontar referências para fora dele, objetivamente. É texto de rápido processamento. Já o texto poético é caracteristicamente opaco, sedutoramente visível; é impactante, provocador de estranhezas; desafiador de sentidos. Não pode nem mesmo ser resumido, pois nessa tarefa perder-se-ia sua essência: "Posso resumir um conceito, mas não posso resumir uma forma" (PIGNATARI, 2004b, p. 24). É impossível passar por ele sem percebê-lo: tornar-se chamativo é sua meta, isto é, revestir-se de uma camada que seja vista, que "incomode", que provoque sensações, seja pela estranheza de suas formas, seja pelos temas centrados no humano que suscita. Na opacidade de sua superfície, guardam-se os "excessos" acionadores do "conhecimento das sensações", conforme explica Zumthor; por isso é um texto imerso em rico universo de "primeiridades" expostas ao sentimento (mais uma vez, ainda aqui entendido como ato de sentir), em função da Qualidade das coisas.

Peirce postula várias tricotomias, cujas categorias, onipresentes, funcionam como "modos coordenados e mutuamente compatíveis pelos quais algo pode ser identificado semioticamente" (Santaella, 2000: 96). Para o semioticista, um símbolo (signo "genuíno", legi-signo) funciona como lei, convenção; guarda em si uma primeiridade, uma secundidade e uma terceiridade. O primeiro corresponde à Qualidade pura das coisas, àquilo que é, num patamar de "pré-existência" sígnica; o segundo corresponde à reação perceptiva a essa 
Qualidade; já o terceiro, à "lei que um existente corporifica" (Idem). Nada impede, porém, que o modo de ser de um signo limite-se ao nível da primeiridade (quali-signo) ou, ultrapassando essa primeiridade, alcance apenas a secundidade (sin-signo), abstraindo-se sua terceiridade.

Assim, o modo de ser de um signo depende do modo como esse signo é apreendido, isto é, do ponto de referência de quem o apreende. Se essa apreensão abstrai o existente individual no qual uma ou várias qualidades inerem, abstrai-se a lei que esse existente atualiza; então, esse ponto de referência retém apenas a qualidade de aparência daquilo que se apresenta, ou seja, seu tout ensemble qualitativo. Nesse caso, temos um primeiro que prescinde do segundo e do terceiro.

Se o ponto de referência abstrai a lei que um existente corporifica e retém deste apenas sua singularidade no aqui e agora da ação e reação perceptiva, temos, então, um segundo que engloba evidentemente as qualidades (nível primeiro) que compõem esse existente, mas prescinde da modalidade do terceiro ou lei. Já no caso de apreensão da lei, esta necessariamente pressupõe um existente no qual toma corpo, assim como este pressupõe as qualidades que nele inerem. [...] Se o fenômeno se apresenta como habitual, armazenado na memória, familiar e, como tal, geral, já funciona automaticamente como signo. Se vem provocando surpresa ou se vem desacompanhado e despojado de qualquer elemento que não seja sua pura "talidade" (sentimentos assim se presentificam) serão seres intermediários, fronteiriços, quase signos: não são mais completamente fenômenos, mas ainda não são inteiramente signos. (SANTAELLA, 2000, p. 96-8)

Pode-se afirmar, portanto, que o texto "comum", é constituído, basicamente, por legisignos; conta com sua terceiridade, com sua "força de lei". Já o texto poético, apesar de, em princípio, ser constituído por legi-signos como os "comuns" (caso contrário não comunicaria nada, nem seria texto), numa segunda perspectiva, mais profunda, presentifica quali-signos a partir das transformações que opera nos legi-signos, das comparações que faz, dos recursos analógicos de que se vale, além de também trabalhar exaustivamente com a reação a esses quali-signos, o que significa dizer que também presentifica sin-signos. Assim, pode-se sustentar que o tipo sígnico característico da poeticidade é o quali-signo; ele é sua "razão de ser", pois a poesia vive da eterna tentativa de (quase) dizer o indizível; de provocar, no leitor, a sensação das Qualidades amorfas de certas existências; de usar exaustivamente estratégias para a apreensão de quali-signos. Camões, ao tentar significar o "insignificável”, diz que "Amor é fogo que arde sem se ver/ É ferida que dói e não se sente". Nas aproximações incomuns que estabelece, o poeta faz surgir determinadas Qualidades, próprias dos seres que foram "aproximados"; ele usa, portanto, quali-signos, ou seja, limita-se às Qualidades exacerbadas por aquela aproximação para chegar o mais perto de uma (impossível) corporificação do Amor, não obtendo um resultado sígnico "com força de lei", mas provocando o sentimento das qualidades que o identificam. Há existentes, como o Amor, que só podem ser "sub-significados" por meio de quali-signos.

Explicando: o quali-signo funciona como signo por intermédio de uma primeiridade da qualidade, qualidade como tal, possibilidade abstraída de qualquer relação empírica espaçotemporal da qualidade com qualquer outra coisa. Exemplo: suponhamos que um professor de dança esteja ensaiando uma determinada configuração das posições do corpo como um todo: certas curvações dos braços, certos pontos de apoio dos pés, certos equilíbrios entre o peso e a leveza do tronco, uma certa inclinação com a cabeça; trata-se, enfim, de um conjunto harmônico que captura a totalidade do corpo na unidade de uma configuração que não pode ser descrita nos fragmentos de suas partes, nem definida verbalmente. É algo que só pode ser 
mostrado e imitado. Para compor seus corpos numa configuração similar àquela que o professor apresenta (presentifica), os alunos abstraem da qualidade dessa configuração tudo que lhes é irrelevante: a diferença específica de cada corpo singular (mais alto, mais baixo, mais gordo ou mais magro, mais jovem ou mais velho), o lugar específico que cada um daqueles corpos ocupa no espaço naquele momento, ou seja: trata-se de reter única e exclusivamente a qualidade in totum com que o corpo aparece no desenho indescritível de sua compleição. (SANTAELLA, 2000, p. 99)

No exemplo de Santaella, o quali-signo seria "extraído" da apreensão das qualidades dos movimentos do professor enquanto dança; ele paira sobre o texto e sobre seu sentido. A partir da percepção visual daquele conjunto, seria possível entender seu "como". O próprio exemplo dado pela autora para dizer o que significa um quali-signo é, ele mesmo, um qualisigno. Quando não é mais possível atribuir um significado exato a algo, tenta-se explorar as características de outra coisa semelhante para, a partir delas, chegar-se próximo ao significado pretendido.

No caso citado, a percepção das características se dá por meio de "sensores físicos", entretanto, poderia ocorrer por meio de "sensores afetivos", de natureza emocional, como acontece muitas vezes no efeito poético. Alimentada somente por "comos", a poesia só existe mediante presentificações oriundas das qualidades das coisas; ela não precisa (nem pode) ser "entendida", "explicada" (como as piadas, se uma poesia é explicada, perde a graça) quando muito, pode ser analisada. Ou melhor, o "entendimento" da poesia é, na verdade, o "sentimento" (ato de sentir) que o quali-signo provoca.

Quando Peirce fala sobre o quali-signo, uma qualidade que é signo, é certo que isso pressupõe uma relação de comparação entre duas qualidades, necessária para que a qualidade funcione como signo. Há inclusa na dimensão monádica do qualitativo a possibilidade pré-sígnica, quase-SIN, mas ainda NÃO-signo, que preside a tudo que, no universo, está sob o desgoverno do acaso, do potencial e, no ser humano, sob a casualidade do sentimento (feeling), única manifestação que, na sua indiscernibilidade, pode caracterizar aquilo que é exclusiva e especificamente humano. Só o sentimento é próprio apenas do homem. [...] O sentimento é tão-só exclusivamente humano, ou melhor, é o tipo específico de manifestação monádica que a espécie humana introduziu no universo. [...] O demônio das associações por semelhança é atiçado justamente pela lei daquilo que é ingovernável. (SANTAELLA, 2000, p. 97-8)

O texto poético traz em si um componente "extra" em relação aos "textos comuns": ele é basicamente original (no sentido dado por Peirce), feito de primeiridades, de qualisignos; se há uma função para o texto poético é a de ser sentido, provocar sentimento: "E o sentimento não é senão mônada ressoante nos influxos das similitudes" (SANTAELLA, 2000, p. 98).

\section{Textos poéticos e as analogias produtoras de quali-signos}

Como visto nos pontos destacados neste trabalho até então, e apesar da sabida coexistência dos pensamentos lógico e analógico, a elaboração poética fundamenta-se em processamentos analógicos, pois são eles os criadores de quali-signos. A poesia trabalha com elementos "indizíveis", mas "caracterizáveis", "experienciáveis". Isso significa dizer que é preciso aproximar e comparar seres para que se produza o efeito poético. 
Para controlar as coisas, o homem precisa digitalizá-las — traduzi-las para a forma de números e palavras (dígito vem do latim digitum, dedo - e implica a idéia de contar). A digitalização é fundamental para as operações mentais, as operações lógicas do pensamento. É fundamental para a ciência e para a tecnologia. Mas a ciência não deixa de lado, completamente, o pensamento analógico, que é o pensamento das formas: o homem também precisa medir e comparar - ele não pode apenas contar. (PIGNATARI, 2004a, p. 51)

$\mathrm{Na}$ aproximação e comparação dos seres (e de suas formas), produzem-se "qualisignos". No texto poético, essa produção pode ser observada a partir de três processos analógicos, relativos aos níveis de construção de sentido: no nível semiolingüístico, a relação intratextual, na combinação incomum das formas presentes na superfície, evidenciando sua seleção; no nível discursivo, a relação intersígnica, na aproximação de um texto a outro, do texto atual a um modelo cognitivo, na intertextualidade; e, no nível situacional, a relação extratextual, na identificação mundo textual /mundo real por meio das escolhas temáticas em que normalmente se baseiam os textos literários.

Quali-signos são produzidos na conjunção dos elementos constitutivos da textualidade poética, por causa de sua necessária originalidade, da singularidade de suas formas e conformações, da evidente projeção do eixo paradigmático sobre o sintagmático. São movimentos que fogem da normalidade do uso comum dos textos, da transparente objetividade dos textos não-poéticos. Ser poético, em termos de materialidade textual, do nível semiolingüístico da linguagem, é ser diferente, estranho, interessante; é produzir uma combinação incomum de formas que se assemelham (de algum modo) e "obrigar" a percepção do processo de seleção, sempre curioso, desafiador, original.

Essa projeção de um eixo sobre o outro numa relação intratextual é a responsável pela "exacerbação" de Qualidades que pertencem a um dos seres combinados e que, por causa da aproximação estabelecida, "impregnam" o outro, quase sempre de maneira inusitada. Nessa "impregnação", paira o quali-signo.

Charles Morris faz uma esclarecedora distinção entre os signos. Diz ele que há signospara e signos-de. Um signo-para conduz a alguma coisa, a uma ação, a um objetivo transverbal ou extraverbal, que está fora dele. É o signo da prosa, moeda corrente que usamos automaticamente todos os dias. Mas quando você foge desse automatismo, quando você começa a ver, sentir, ouvir, pesar, apalpar as palavras, então as palavras começam a se transformar em signos-de. Fazendo um trocadilho, o signo-de pára em si mesmo, é signo de alguma coisa - quer ser essa coisa sem poder sê-lo. Ele tende a ser um ícone, uma figura. É o signo da poesia. [...] o signo-para é um signo por contigüidade, enquanto o signo-de é um signo por similaridade. (PIGNATARI, 2004b, p. 11)

De acordo com Morris, o texto poético é feito de "signos-de", que querem ser a coisa que significam, sem poder sê-lo (e correspondem aos quali-signos de Peirce). É o caso, por exemplo, da frase "Era apenas/o frágil e/feio/e aflito/Flicts (ZIRALDO, 1999, p. 11). A aliteração (que evidencia a combinação incomum de formas que se assemelham por causa da sonoridade) não só acentua a identificação do personagem Flicts com características depreciativas (frágil, feio e aflito), como também, ao reiterar o som fricativo lábio-dental como o de quem bufa, remete o estado de ânimo do personagem à idéia de desconforto, rejeição, esmorecimento. Percebem-se os "excessos de sensações" provocados por essa combinação incomum, que explora a seleção em virtude da Qualidade que quer expressar.

Da mesma maneira, são "signos-de" os neologismos criados por Ziraldo (1994) em Uma historinha sem (1) sentido: zip-zap-urgência, zzzz-ressonando, tchan-distância etc. São 
eles também combinações incomuns de formas que se assemelham, neste caso, nas relações entre a onomatopéia e a palavra que a acompanha: aquela corrobora a expressão do significado desta a partir da situação que evoca com sua sonoridade: zip-zap remete à situação de rapidez, de urgência, como algo que vai e volta correndo, produzindo o som representado pela onomatopéia; zzzz imita o som do ressonar e já é fórmula fixa das histórias em quadrinhos para representar alguém dormindo, ressonando; tchan está vinculado ao suspense, talvez como forma abreviada de trecho da sinfonia de Beethoven, usada como fundo musical para situações de medo, de aventura; no caso, da distância a ser saltada.

Essa "novidade textual" apresenta ainda outro papel: motivar um forte impacto, ou um "estado de alerta" no leitor. É preciso aceitar o desafio de entendimento dessas combinações inusitadas, senão estará condenado a não usufruir o texto, a não desfrutar das sensações que ele provoca. A busca de compreensão dessas "surpresas textuais" representa a possibilidade do sentimento (feeling), de alcance do prazer sugerido pelo texto.

Em outra instância, o vínculo com a Qualidade, com a primeiridade das coisas, aparece também nas várias similitudes provocadas pelas relações intersígnicas, do texto em relação com o mundo, ou com outros textos. Analogicamente, por aproximações em virtude das Qualidades dos seres, imagens são suscitadas, seja por meio de "imitações" da realidade, seja por meio de figuras de linguagem, seja por meio de processos intertextuais, ou de convergência sincrética. $O$ confronto com o que há de semelhante é, na verdade, o confronto com a Qualidade; é sua exacerbação; é explorar a primeiridade presente na relação "entre signos". Neste caso, temos analogias baseadas, sobretudo, em relações do nível discursivo da linguagem.

Por exemplo, em $O$ menino quadradinho (ZIRALDO, 1989), a expectativa da presença de um menino é criada a partir da apresentação de uma bola, um tênis, uma cafifa, um skate, desenhados, figurativizando elementos do mundo real; imitando-os: como os outros elementos, a bola desenhada é toda e qualquer bola e apresenta as qualidades básicas para ser reconhecida como tal. A Qualidade de ser brinquedo desses elementos os qualifica como caracterizadores de um menino, por isso criam aquela expectativa. Em outras palavras, esses elementos antecipam a presença da criança presentificando sua Qualidade de brinquedo, intimamente ligada à Qualidade de ser criança.

Nesse livro, outro caso interessante: as letras grandes, desenhadas e preenchidas das mais diversas maneiras (observem-se as Qualidades destacadas) são como as de uma história em quadrinhos, que abusam de recursos plásticos; à medida que o menino cresce, elas diminuem progressivamente até assumirem uma forma como as letras de um romance, pequenas, uniformes, sem o acompanhamento de ilustrações. A gradativa substituição de um tipo de letra por outro remete — analogicamente — à substituição dos quadrinhos por romances, conforme se dá enquanto o leitor amadurece e se torna experiente. Essas analogias se deram aproveitando conhecimentos do nível discursivo da linguagem, mas, acima disso, em função das Qualidades dos elementos (das letras).

Ainda outra vez, o processo analógico pode ser verificado por meio da intertextualidade: com a frase "Trouxeste a chave", aproxima-se o texto de Ziraldo ao de Drummond, de onde o verso fora extraído, tornando-os, ainda que parcialmente, parecidos. Nesse "ponto de contato", as palavras são "suporte" de suas Qualidades transferidas, que podem atribuir ao "enxertado" a idéia de ser enigmático, desafiador, opaco. Como nos outros casos mencionados, essas Qualidades não são denominadas, mas (pré)sentidas no confronto dos seres aproximados. Essas Qualidades (pré)sentidas são o que chamamos aqui de qualisignos. 
Também é de responsabilidade dos quali-signos a sensação de amadurecimento experimentada pelo leitor de $O$ menino mais bonito do mundo (ZIRALDO, 1994) quando, paralelamente à leitura de um texto verbal que revela a evolução cronológica dos fatos, vê-se a transformação dos traços das ilustrações, que vão se tornando, aos poucos, cada vez mais firmes, seguros, detalhados, como se trocassem os traços de uma criança pelos de um adulto. O ponto de vista do leitor coincide com o do protagonista e, por seus olhos, ele vê o mundo representado nas ilustrações se modificar, esclarecer-se, significando, assim, o amadurecimento desse protagonista (ao qual o leitor adere inclusive pela posição oferecida a ele pelo texto). Esse é um exemplo de convergência sígnica: conhecimentos paralelos e aparentemente isolados, apreendidos em meios sígnicos diversos (verbal e icônico), vão largando excedentes de sensação (quali-sígnicos) muito semelhantes, até que se perceba a coincidência de sua Qualidade, a convergência desses sentimentos com o propósito de imprimir no leitor a sensação de "tornar-se homem adulto".

São muitos os exemplos que se valem da aproximação de objetos semelhantes para que suas qualidades sejam exploradas, como se fossem apresentadas antes mesmo de ter-se consciência dos objetos a que se vinculam. Assim, o poeta tenta expressar, pelas parecenças, algo considerado inexprimível.

A poesia situa-se no campo do controle sensível, no campo da precisão da imprecisão. A questão da poesia é esta: dizer coisas imprecisas de modo preciso. As artes criam modelos para a sensibilidade e para o pensamento analógico. Uma poesia nova, inovadora, original, cria modelos novos para a sensibilidade: ajuda a criar uma sensibilidade nova. (PIGNATARI, 2004a, p. 53)

Da mesma forma, é percebida a exploração da primeiridade própria do que é Qualidade nas escolhas temáticas comuns aos textos poéticos, relacionando mundo textual/mundo real: porque falam a respeito de ser humano, a consciência de nossa humanidade automaticamente coloca o leitor (e suas experiências que, afinal, o constituem) em relação icônica com a realidade expressa pelo texto; há identificação; o eu que habita o leitor assemelha-se ao eu do mundo textual, justamente por causa da semelhança humana/humanística, que fatalmente emergirá das situações criadas no texto.

O herói que usa seus cinco sentidos para escapar dos perigos em Uma historinha sem (1) sentido representa o ser humano, que conta com sua percepção sensorial para entrar em contato com o mundo, mas que precisa, além ou acima disso, de contar com a leitura como um sentido a mais; o menino mais bonito do mundo representa todo ser humano, e cada um de nós em particular, em sua necessidade do Outro; o personagem Flicts, discriminado, representa todo aquele que alguma vez sentiu-se rejeitado por uma qualidade diferente; finalmente, o menino quadradinho representa o leitor em formação, como aquele que assume, aos poucos, o texto exclusivamente verbal e sabe extrair dele não só conhecimento, mas prazer, deleite. É como se o leitor fosse cada um deles e sentisse as Qualidades ali suscitadas pelas analogias como suas: ele, como sujeito-interpretante (empírico) adere ao projeto de um sujeito-destinatário implicitado no texto pelo sujeito-comunicante-autor. É do lugar em que se encontra que essa adesão ocorre; se isso acontece, pode-se afirmar que houve uma perfeita comunhão entre os fatores de intencionalidade e de aceitabilidade do texto. Neste caso, observa-se o leitor investindo em elementos do nível situacional da linguagem.

Não seria possível explicar essas condições somente descrevendo-as — ou talvez até se pudesse descrevê-las, mas o sentido dessa descrição seria apenas intelectivo, informativo. Só é possível saber essas condições em profundidade, conhecendo-as verdadeiramente, criando um sentido-sensação, fazendo com que o leitor se identifique com as personagens e 
com as situações, tornando-o idêntico a elas, a fim de transportá-lo para o mundo textual, ao mesmo tempo em que o mundo textual se transporta para o mundo real do leitor. Ter o amor como referência "distante" (ou o amadurecimento, ou a rejeição etc.) não é sentir o amor; mas, por meio das provocações que o texto opera, é possível experimentar sua sensação. Assim, no processo identificatório operado pelo leitor, trabalha-se, mais uma vez, a primeiridade, a Qualidade daquilo que é "sentido", mas que não pode ser explicado (a não ser vagamente).

\section{A sensação das qualidades no poético por meio de "mão alheia"}

Ser um texto poético pressupõe, portanto, constituir-se de estratégias que visam a primeiridades. O prazer do texto poético advém daí, dessas primeiridades intraduzíveis, sem significado (isto é, sem ainda transformar-se em signo), que marcam profundamente, muitas vezes inconscientemente, aquele que lê. O que se assemelha a outra coisa não é a outra coisa; o que interessa daquela outra coisa aproximada por uma semelhança é apenas a qualidade que as identifica. É preciso conhecer (ou sentir) a Qualidade e isso acontece no processo analógico; uma primeiridade pode ser sentida quando essa Qualidade é exacerbada e detectada, embora nem sempre possa ser "traduzida" em signo. Para ser um leitor competente de textos poéticos (e saber fruir) é preciso, além das habilidades semiolingüísticas, discursivas e situacionais, ter a capacidade de perceber as Qualidades expressas indiretamente por meio das analogias. Só dessa maneira o leitor atingirá o sentido-sensação, o gosto do texto e, afetado pelo texto, perceberá a re-novação, a trans-formação já consumada. Dessa forma, pode-se postular, quanto ao efeito poético, um princípio: a poesia existe quando, a partir de analogias, são suscitadas Qualidades a fim de delimitar o inexprimível.

Se "ler é uma forma de escrever com mão alheia", ler textos como os de Ziraldo pressupõe essa competência fruitiva que dispõe o leitor às Qualidades do texto. No entanto, como leitor, a construção do sentido só é provável se, em contato com o texto, houver uma adesão ao projeto sígnico proposto pelo conjunto verbal/não verbal. Escreve-se com mão alheia porque há uma capacidade humana baseada na alteridade: somos o que somos porque podemos ser um pouco o Outro, sobretudo quando nos deixamos afetar, quando, também numa interação analógica com o texto, identificamo-nos, deixamo-nos tornar iguais a ele e a seus elementos, construindo sentidos a partir daqueles que pertenciam ao Outro e que nos foram oferecidos por meio, sobretudo, do texto poético, particularmente propício à sensação das qualidades.

\section{Referências Bibliográficas}

ALMEIDA, Fernando Afonso de. Linguagem e humor: comicidade em Les frustés, de Claire Bretécher. Niterói, RJ: EdUFF, 1999.

ARAÚJO, Inês Lacerda. Do signo ao discurso: introdução à filosofia da linguagem. São Paulo: Parábola Editorial, 2004.

CHARAUDEAU, Patrick. De la competencia social de comunicación a las competencias discursivas. In: Revista interamericana de estudios del discurso - ALED, Venezuela: Editorial Latina, volume I, número 1, pp. 7-22, agosto de 2001. 
CASA, Vol.4, n.2, dezembro de 2006

Langages et discours. Paris: Hachette, 1983.

COSERIU, Eugênio. Lições de lingüística geral. Rio de Janeiro: Ao Livro Técnico, 1980.

JOLY, Martine. Introdução à análise da imagem. 7.ed. São Paulo: Papirus, 1996.

PEIRCE, Charles. Semiótica. 3.ed. São Paulo: Perspectiva, 2003.

PIGNATARI, Décio. O que é comunicação poética. 8.ed. Cotia - São Paulo: Ateliê Editorial, 2004a.

Semiótica e literatura. 6.ed. Cotia - São Paulo: Ateliê Editorial, 2004b.

SANTAELLA, Lúcia. A teoria geral dos signos: como as linguagens significam as coisas. São Paulo: Editora Pioneira, 2000.

SANT'ANNA, Affonso Romano de. Ler o mundo: tudo é texto. Não é só quem lê um livro que lê. In: $O$ Globo, s/d.

ZIRALDO Alves Pinto. Flicts. 36.ed., São Paulo: Melhoramentos, 1999.

. O menino mais bonito do mundo. Ilustr. por Sami Mattar e Apoena H. G. Medina. 15.ed.,São Paulo: Melhoramentos, 1994a.

O menino quadradinho. 12.ed. São Paulo: Melhoramentos, 1989.

. Uma historinha sem (1) sentido. 10.ed. São Paulo: Melhoramentos, 1994 b.

ZUMTHOR, Paul. Percepção, recepção, leitura. São Paulo: EDUC, 2000. 